\title{
Anatomía Microscópica de las Glándulas Salivales por Medio de una Técnica Histológica Convencional y no Convencional
}

\author{
Microscopic Anatomy of the Salivary Glands for Mean \\ of Conventional and not-Conventional Histologic Technique \\ "Iván Claudio Suazo Galdames \& Ignacio Javier Roa Henríquez
}

SUAZO, G. I. C. \& ROA, H. I. J. Anatomía microscópica de las glándulas salivales por medio de una técnica histológica convencional y no convencional. Int. J. Morphol., 26(3):689-695, 2008.

RESUMEN: Las técnicas de fijación y conservación permiten detener los procesos de desorganización de los tejidos y son necesarios para analizar la anatomía microscópica de ellos. El propósito de este estudio fue analizar las características histológicas de las glándulas parótida y submandibular obtenidas a partir de tres cadáveres humanos fijados y conservados mediante: a) solución conservadora en base a formaldehido (muestra I) y b) cámara de frío por 12 horas (muestra II), ambas muestras procesados para hematoxilinaeosina (H-E); c) plastinación con resina epóxica (muestra III) y procesado para H-E y con azul de metileno- eosina sin inclusión previa. Se analizaron las características de los adenómeros y sistema de conductos glandulares. Las mejores características se encontraron en la muestra II, con un buen nivel de detalle en el parénquima glandular, una mayor basofilia se presentó en la muestra I. La muestra III presentó un bajo nivel de detalle a la observación microscópica, los mejores resultados se obtuvieron utilizando azul de metileno. Las mayores dificultades en el procesamiento histológico de las piezas plastinadas se encontraron en el corte y en el tiempo necesario para la tinción. Los resultados sugieren que es posible obtener preparaciones histológicas a partir de necropsias en cadáveres fijados y conservados para la docencia e investigación anatómica.

PALABRAS ClAVE: Técnica histológica; Plastinación; Fijación; Conservación; Glándulas salivales.

\section{INTRODUCCION}

El estudio de la anatomía requiere del empleo de métodos de fijación y conservación de los tejidos que detengan los procesos degenerativos postmortem. Algunos de estos métodos se conocen hace más de 3000 años (embalsamamiento en Egipto), no obstante los pasos más importantes se dieron luego de la introducción de la formalina y otras soluciones conservadoras, junto con la utilización de soluciones coloreadas polimerizables en los territorios vasculares, que favorecieron su uso con fines docentes y de investigación (Weiglein, 2002).

Von Hagens (1979) en la Universidad de Heidelberg introdujo un método de fijación y conservación denominado plastinación, en el cual el agua y lípidos presentes en las células y tejidos mediante la impregnación forzada de polímeros curables de silicona, resina epoxica o poliester que endurecen dando como resultado la obtención piezas anatómicas secas, inodoras y durables (Bose, 1985). La téc- nica de plastinación permite la obtención de cadáveres completos, partes o secciones de ellos y desde su introducción ha producido una verdadera revolución en la enseñanza y la investigación de la anatomía macro y mesoscópica (von Hagens et al., 1987, Graf et al., 1990, Eckel et al., 1993, O'Sullivan \& Mitchell, 1995, Simank et al., 1995, Cook, 1997, Weiglein, 1997, Cohn, 2002, Lozanoff, 2002, Sora et al., 2002, Dhingra et al., 2006, Kcn et al., 2007, Latorre et al., 2007, Bravo, 2006).

Para el estudio histológico e histopatológico es necesario que las estructuras a analizar conserven al máximo las características morfológicas de las células y tejidos. La fijación de las glándulas salivales mayores para análisis microscópico se realiza habitualmente por inmersión en formalina de una pieza obtenida por biopsia incisional o mediante la necropsia del órgano realizada próxima a la muerte. Las características histológicas de las glándulas salivales obteni- 
das mediante necropsia realizada a partir de cadáveres fijados y conservados mediante soluciones en base a formaldehido o plastinados se encuentran insuficientemente descritas.

Por otra parte el proceso de inclusión en parafina descrito para la técnica histológica convencional, tiene como fundamento la necesidad de aportar la rigidez necesaria al bloque de tejido para que pueda ser cortado en el micrótomo. En el caso de las piezas plastinadas, la rigidez aportada por el polímero, permitiría la obtención de segmentos de grosores adecuados para el examen de las características microscópicas del tejido.

Con estos antecedentes, el propósito de este estudio es analizar las características histológicas de las glándulas parótida y submandibular obtenidas a partir de cadáveres humanos fijados y conservados por tres medios distintos.

\section{MATERIAL Y MÉTODO}

Se realizó el análisis histológico de las Glándulas Parótida y Submandibular, obtenida mediante la necropsia de cadáveres conservados por tres medios distintos:

Muestra I. Necropsia de glándula parótida y submandibular izquierda obtenida de un cadáver adulto de sexo masculino 55 años de edad de nacionalidad española. Data de muerte 2 años 4 meses.

Procedimientos de conservación: Conservado en cámara de frío por 12 horas, luego fijado y conservado mediante inyección intravascular de solución conservadora a base de formaldehido y el territorio arterial fue repletado con látex de color rojo.

Muestra II. Adulto sexo masculino 46 años de edad, de nacionalidad chilena, con una data de muerte de 12 horas y conservado en cámara de frío, del cual se obtuvieron la glándula Parótida y Submandibular del lado izquierdo, en el momento de la necropsia.

Muestra III. Necropsia de glándula parótida y submandibular derecha plastinadas, obtenidas de un cadáver adulto sexo masculino, 67 años, de nacionalidad chilena. Data de muerte 12 años.

Procedimientos de conservación: Conservado en cámara de frío por 12 horas, luego fijado y conservado con solución conservadora en base a formaldehido por 10 años y finalmente conservado mediante técnica de plastinación con resina epóxica (Biodur TM Products, Heidelberg, Germany).

Técnicas de Histoplastinación. Tanto las muestras obtenidas de los sujetos I y II fueron procesadas de manera habitual para Hematoxilina y Eosina.

Debido a la rigidez del bloque plastinado permitió el corte, las muestras plastinadas no fueron incluidas en parafina y se procedió a realizar la técnica histológica a partir del corte:

Técnica de Histoplastinación Hematoxilina/Eosina ( $\left.\mathrm{N}^{\circ} 1\right)$.

La muestra plastinada sin ser incluida en un taco de parafina fue cortada con navaja de micrótomo R35 (Feather Safety Razor Co. Ltd., Japan) a mínimo espesor logrado (aproximadamente $600 \mu \mathrm{m}$ ), luego los cortes se procedieron a teñir mediante técnica de flotación en:

- $\quad$ Hematoxilina por 8 minutos.

- $\quad$ Enjuague en agua corriente (segundos).

- $\quad$ Agua amoniacal por 1 minuto.

- $\quad$ Enjuague en agua corriente (segundos).

- $\quad$ Eosina por 4 minutos.

- $\quad$ Enjuague en agua corriente (segundos).

Luego se procedió a deshidratar y aclarar de la siguiente manera:

- $\quad$ EtOH I sumergir 1 vez.

- $\quad$ EtOH II sumergir 2 veces.

- $\quad$ EtOH III sumergir 3 veces.

- $\quad$ EtOH IV sumergir por 1 minuto.

- $\quad$ Xilol I sumergir por 2 minutos.

- $\quad$ Xilol II sumergir por 2 minutos.

- $\quad$ Xilol III sumergir por 2 minutos.

Técnica de Histoplastinación Azul de Metileno/Eosina (N²).

El corte de la muestra plastinada se realiza con navaja de micrótomo R35 (Feather Safety Razor Co. Ltd., Japan) a mínimo espesor logrado (aproximadamente 600 $\mu \mathrm{m})$, luego los cortes se proceden a teñir mediante técnica de flotación en:

- $\quad$ Azul de metileno al 1\% por 10 minutos.

- $\quad$ Enjuague en agua corriente (segundos).

- $\quad$ Agua amoniacal por 1 minuto.

- $\quad$ Enjuague en agua corriente (segundos).

- $\quad$ Eosina por 4 minutos.

- Enjuague en agua corriente (segundos).

Los cortes obtenidos fueron analizados con micros- 
copio óptico Carl Zeiss 0.25 Standard (Germany) y las imágenes obtenida con cámara digital Samsung Digimax S500 a aumentos de 10 y $40 \mathrm{x}$, las cuales fueron analizadas con el software Macromedia Frehand Mxa.

Los parámetros utilizados para hacer el estudio comparativo de la morfología en los distintos tipos de preservación fueron:

- $\quad$ Identificación de adenómeros.

- Identificación de sistema de conductos.

\section{RESULTADOS}

Con respecto a la morfología de la glándula parótida en las imágenes obtenidas de las muestras I y II podemos apreciar gran cantidad de adenómeros serosos típicos, entre los cuales podemos apreciar con claridad un cierto número de conductos estriados y conductos terminales en medio de un tabique de tejido conectivo fibroso laxo. En las Figs. 1, $2,3,4$, se observan las microfotografías de las muestras I y II de parótida teñidas con hematoxilina eosina. Con respecto a las muestras de la muestra III (Figs. 5 y 6) se aprecian adenómeros y conductos más claramente en las teñidas con el método $\mathrm{N}^{\circ} 2$, podemos ver el contorno de los adenómeros y la distribución de los núcleos, además de la morfología celular de los distintos conductos. Además es posible apreciar en este último grupo estructuras redondeadas no pigmentadas, las cuales podrían ser correspondientes a la resina con la cual fue plastinado el espécimen.

Los resultados encontrados en la submandibular son semejantes a los que observados en la parótida donde tanto en las muestras I y II podemos apreciar adenómeros, con-

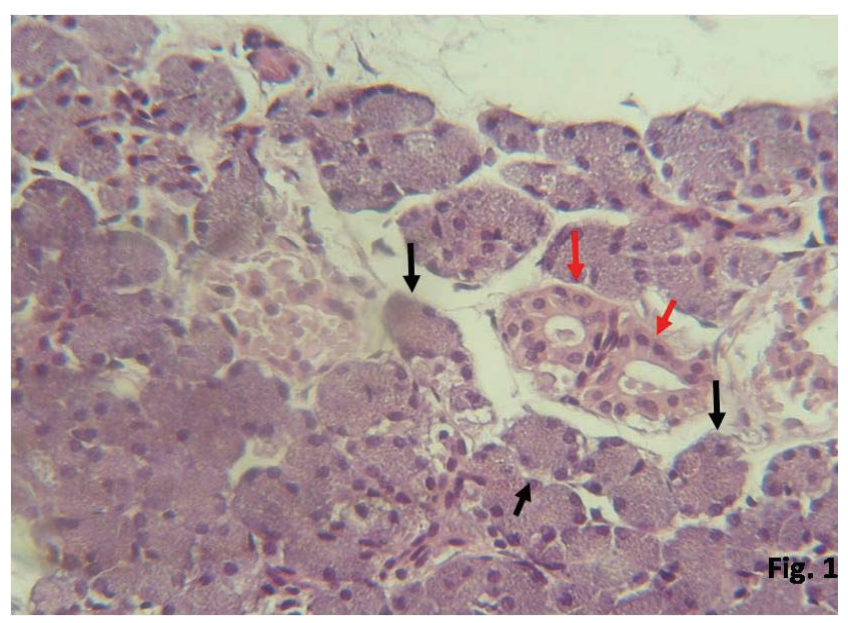

Fig. 1. Glándula parótida de muestra I, se aprecian adenómeros serosos (flechas negras) y conductos estriados (flechas rojas). H/E, $\mathrm{x} 40$.

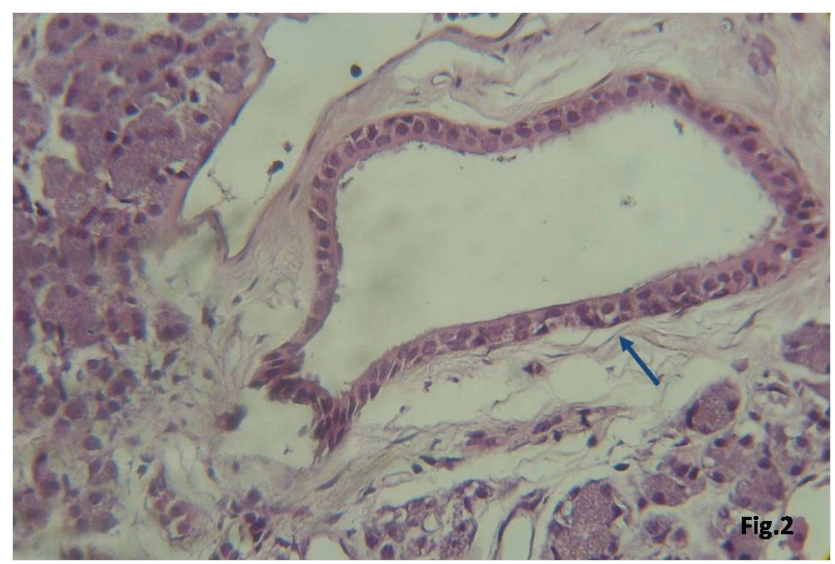

Fig. 2. Glándula Parótida de muestra I, se observa un conducto terminal (flecha azul), nótese la pseudoestratificación de este. H/E. x 40.

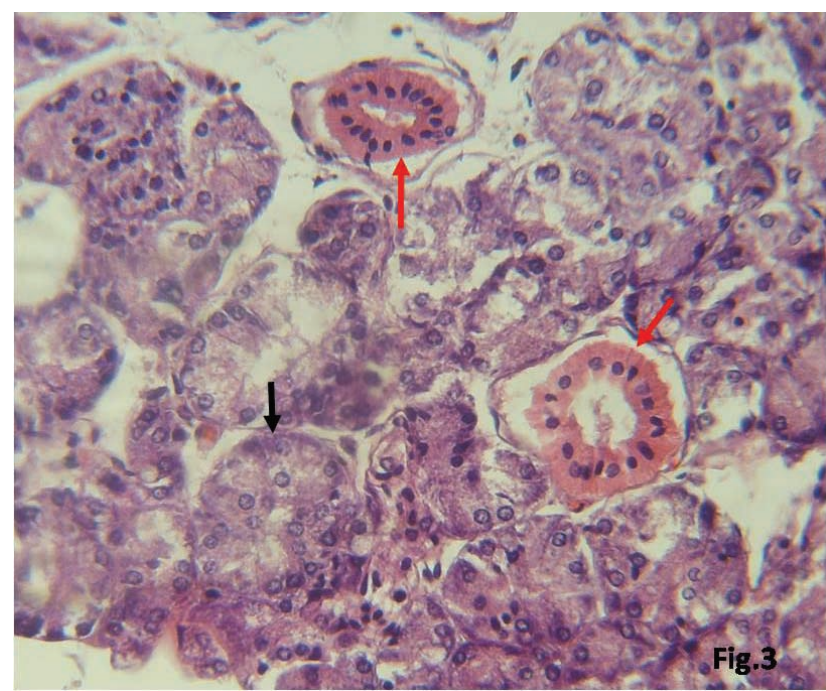

Fig. 3. Glándula Parótida de muestra II, podemos apreciar un adenómero seroso (flecha negra) y dos conductos estriados (flechas rojas). H/E, x 40 .

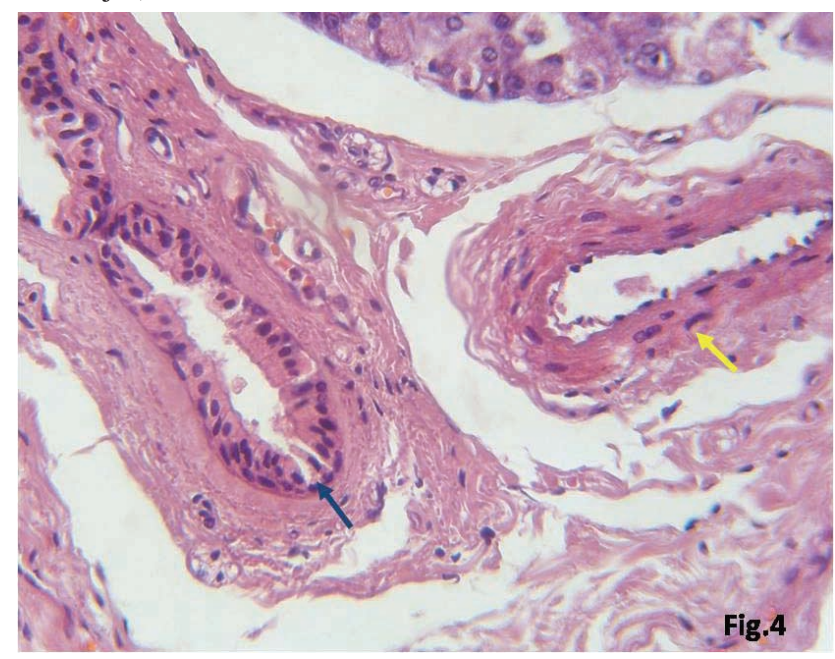

Fig. 4. Glándula Parótida de muestra II, podemos observar un conducto terminal (flecha azul) y un vaso sanguíneo (flecha amarilla), en medio del tejido conectivo del tabique glandular. H/E, x 40. 


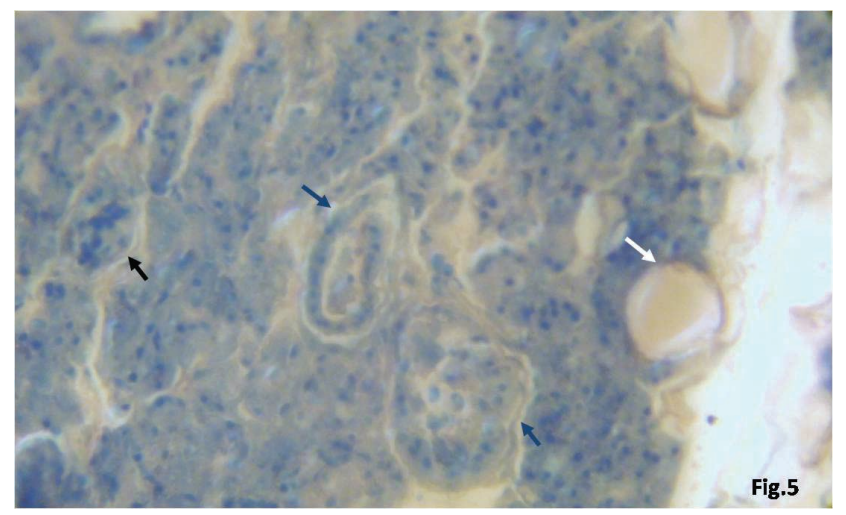

Fig. 5. Glándula Parótida de muestra III, Método Tinción $\mathrm{N}^{\circ} 2$, adenómero seroso (flecha negra) y conductos estriados (flechas azules), vesícula de silicona (flecha blanca). Azul de metileno/ Eosina. x 40 .

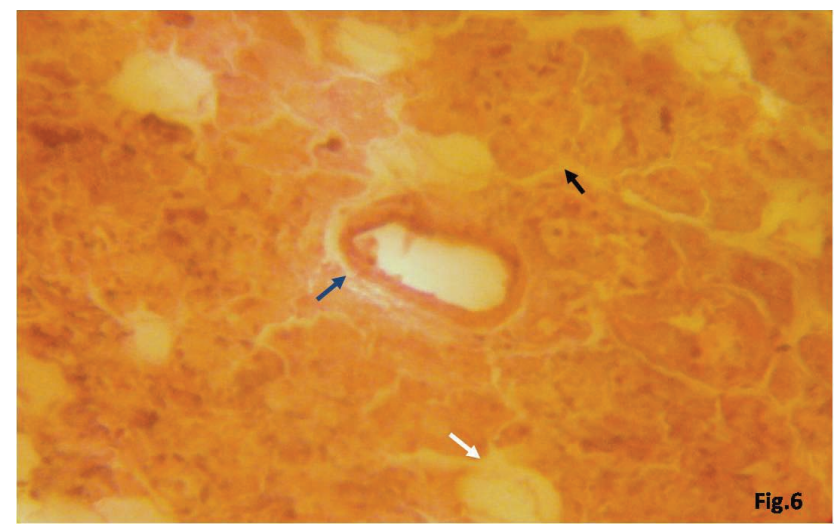

Fig. 6. Glándula Parótida de muestra III, Método Tinción $\mathrm{N}^{\circ} 1$, observamos un adenómero seroso (flecha negra), un conducto terminal (flecha azul), y una vesícula de silicona (flecha blanca) H/E. x 40 .

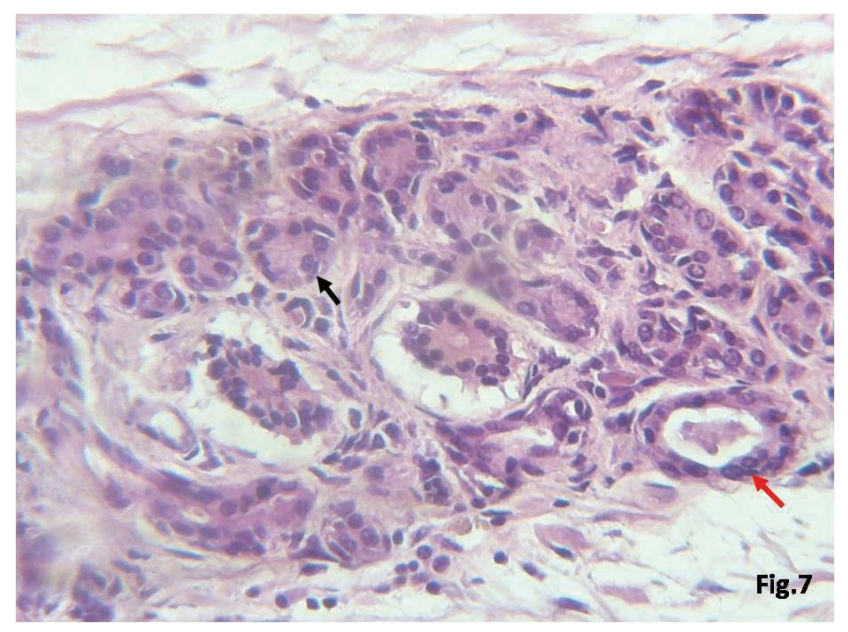

Fig. 7. Glándula submandibular de muestra I, podemos ver un adenómero seroso (flecha negra) y un conducto estriado (flecha roja). H/E, x 40 .

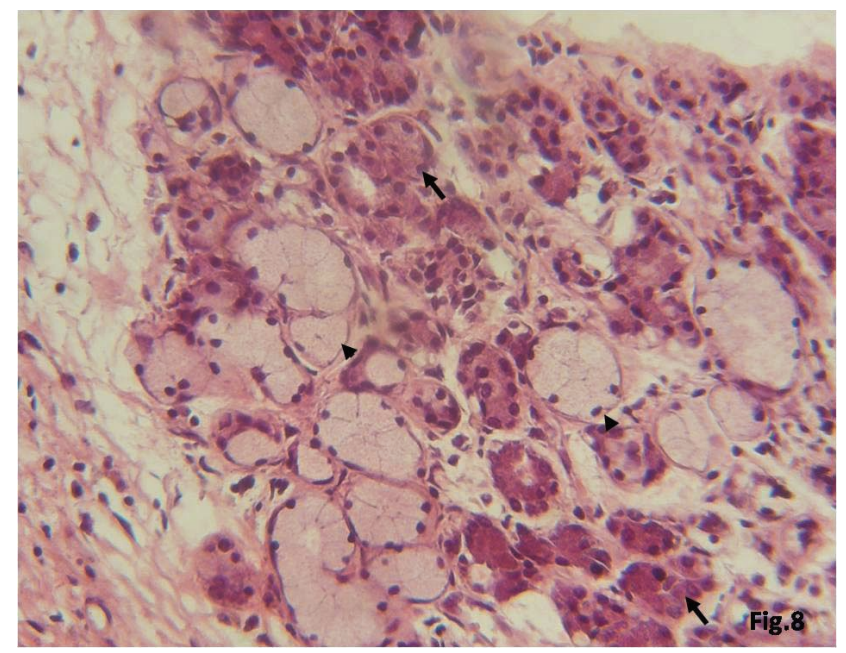

Fig. 8. Glándula submandibular de muestra I, adenómeros serosos (flechas negras) y mucosos (puntas de flechas). H/E. x 40.

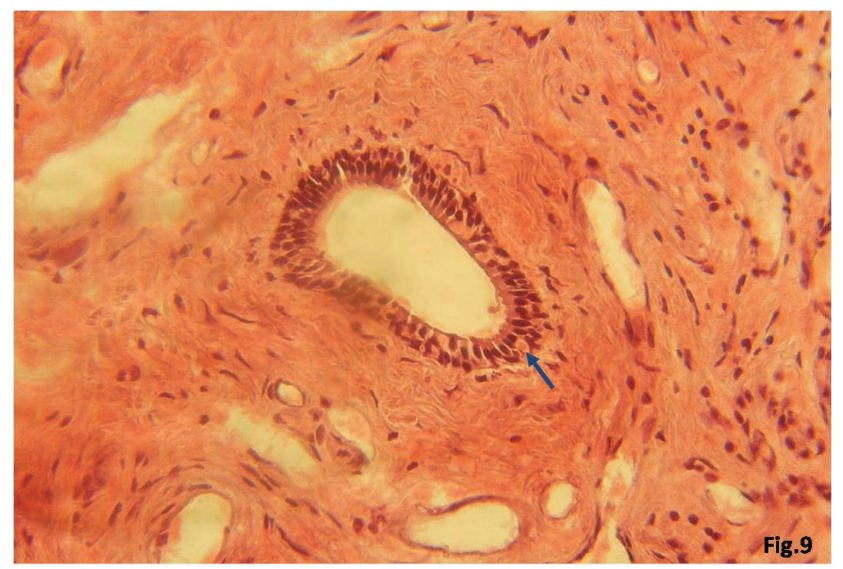

Fig. 9. Glándula submandibular de muestra I, podemos ver conducto terminal en el centro de tejido conectivo del tabique glandular (flecha azul). H/E. x 40.

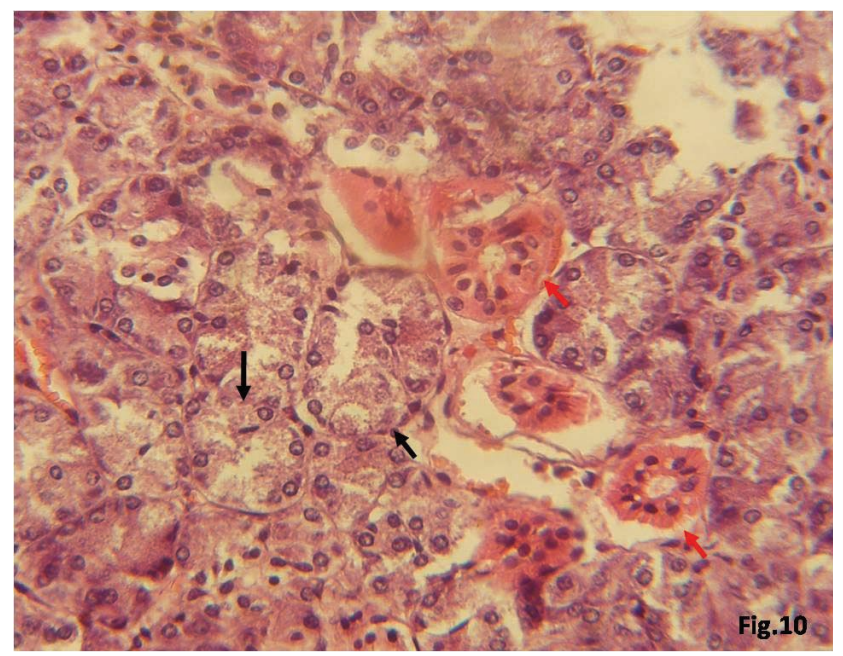

Fig. 10. Glándula submandibular de muestra II, adenómeros serosos (flechas negras), conductos estriados (flechas rojas). H/E. x 40. 


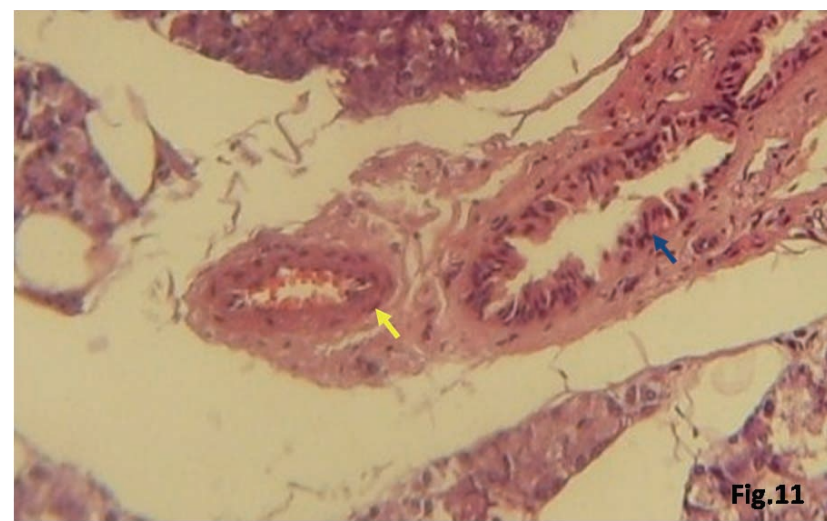

Fig. 11. Glándula submandibular de muestra II, conducto terminal (flecha azul) y vaso sanguíneo (flecha amarilla). H/E. x 40.

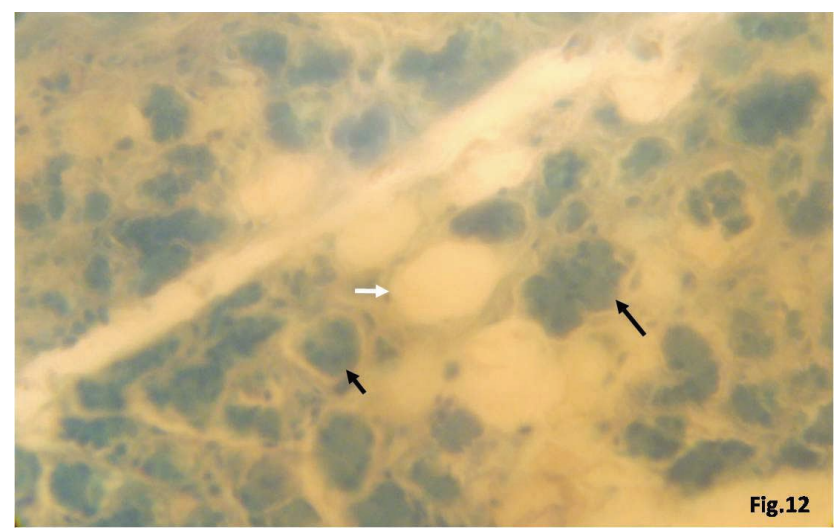

Fig. 12. Glándula submandibular de muestra III, Método Tinción $\mathrm{N}^{\circ} 2$, adenómeros serosos (flechas negras), vesícula de silicona (flecha blanca). Azul de metileno/Eosina. x 40.

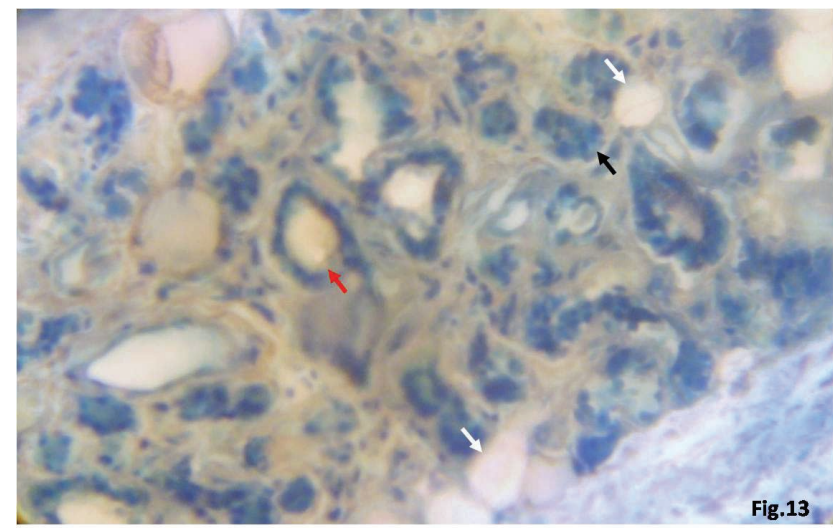

Fig. 13. Glándula submandibular de muestra III, Método Tinción $\mathrm{N}^{\circ} 2$, adenómero seroso (flecha negra), conducto estriado (flecha roja), vesícula de silicona (flecha blanca). Azul de metileno/ Eosina, x 40.

ductos estriados y conductos terminales. En las Figs. 7, 8, 9, 10 y 11, se observan las microfotografías de las muestras I y II de glándula submandibular teñidas con hematoxilina

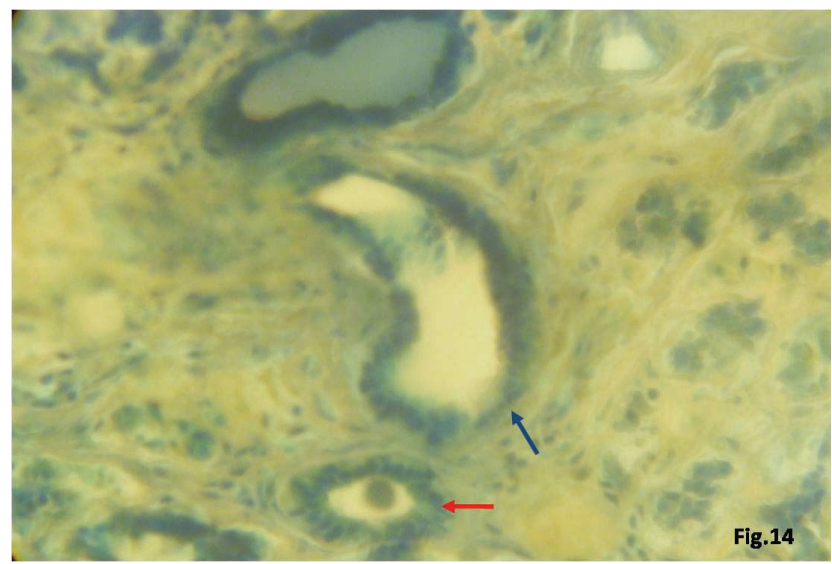

Fig. 14. Glándula submandibular de muestra III, Método Tinción $\mathrm{N}^{\circ} 2$, podemos apreciar un conducto terminal (flecha azul) y conducto estriado (flecha roja). Azul de metileno /Eosina. x 40.

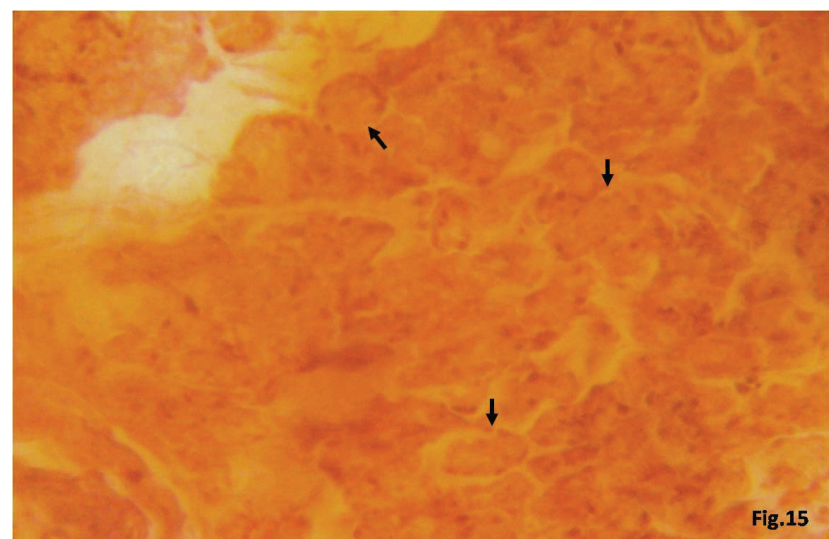

Fig. 15. Glándula submandibular de muestra III, Método Tinción $\mathrm{N}^{\circ}$, podemos ver adenómeros serosos (flechas negras). H/E. x 40.

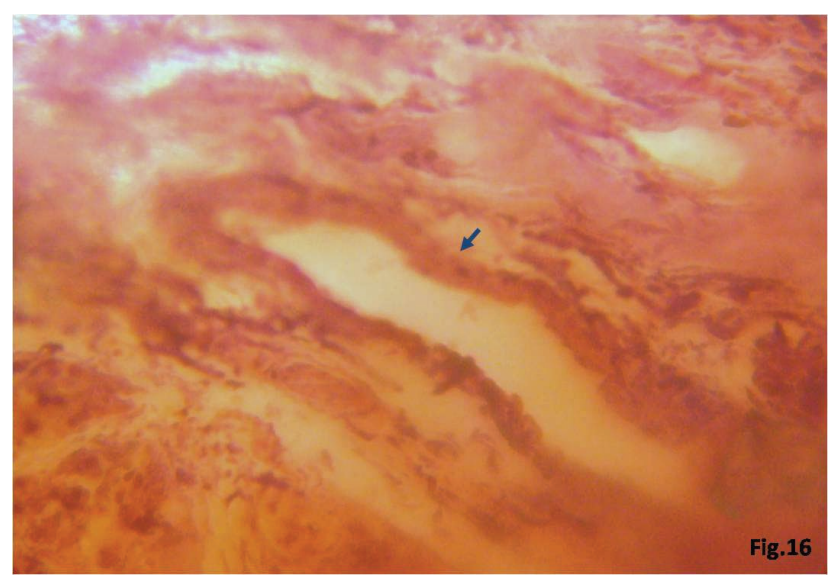

Fig. 16. Glándula submandibular de muestra III, Método Tinción $\mathrm{N}^{\circ} 1$, apreciamos un conducto terminal (flecha azul), en medio de un tabique conjuntivo. H/E. x 40 .

eosina. Al igual que en la parótida de la muestra III se aprecian adenómeros y conductos más claramente en las teñidas con el método $\mathrm{N}^{\circ} 2$. Además es posible apreciar, en este 
último grupo, estructuras redondeadas no pigmentadas, que corresponden a acúmulos de resina con la cual fue plastinado el espécimen. En las Figs. 12, 13, 14, 15, 16 y 17, se observan las microfotografías de las muestras III de glándula submandibular teñidas con hematoxilina eosina y con azul de metileno - eosina.

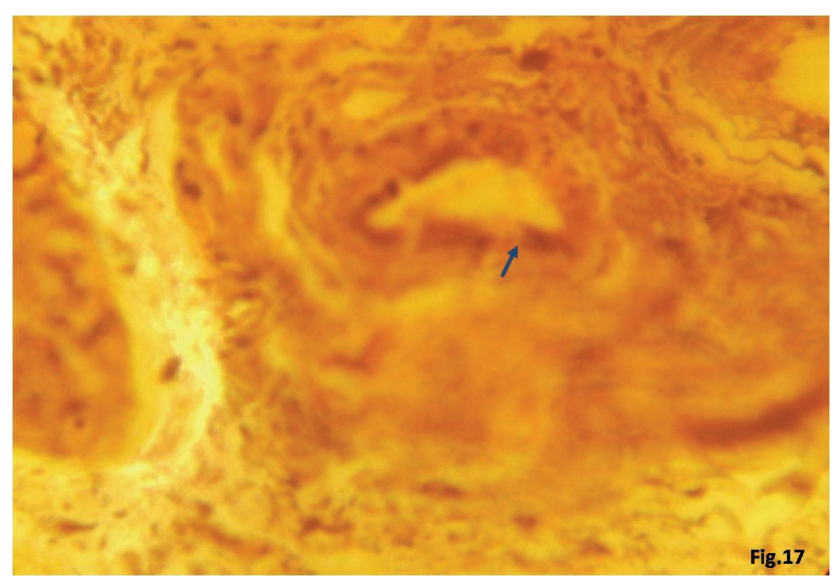

Fig. 17. Glándula submandibular de muestra III, Método Tinción $\mathrm{N}^{\circ} 1$, podemos apreciar un conducto terminal (flecha azul). H/E. $\mathrm{x} 40$.

\section{DISCUSIÓN}

La observación de la anatomía microscópica de las glándulas salivales requiere de métodos adecuados de fijación de los tejidos. Las técnicas histológicas convencionales utilizan tejidos fijados en soluciones en base a formaldehido. En este estudio analizamos las características morfológicas de preparaciones histológicas de glándulas parótida y submandibular obtenidas de cadáveres fijados y conservados utilizando métodos distintos.

El tratamiento de la muestra II fue el más semejante al procedimiento de biopsia y razonablemente arrojó los mejores resultados para la observación del parénquima glandular. La conservación en frío permitió la conservación de la mayor parte de las características morfológicas de las glándulas observadas.

El método realizado en la muestra I tuvo resultados satisfactorios, con éste método se logró un buen nivel de detalle para los adenómeros y conductos glandulares, esto indica que la inyección por vía vascular de una solución conservadora en base a formaldehido permite fijar y conservar los tejidos de órganos bien vascularizados, como las glándulas salivales, durante un tiempo prolongado, en este transcurrieron más de dos años desde la data de muerte. No obstante estos resultados, es necesario evaluar la utilidad del método en tejidos menos vascularizados como el hueso o cartílago. Por otra parte, no fue posible encontrar residuos de látex coloreado en los vasos de pequeño calibre observados, probablemente el tamaño de la molécula dificulte su ingreso en ese nivel.

En el caso del cadáver plastinado, las técnicas utilizadas fueron complejas. La principal dificultad se encontró al realizar el corte. El grosor del corte de nuestras preparaciones fue de $600 \mu \mathrm{m}$, aunque la literatura reporta el uso de grosores de hasta $100 \mu \mathrm{m}$, no fue posible reproducirlos (Seibold et al., 1991, Sittel et al., 1996, Hoch et al., 2004, Nash et al., 2005). Otra dificultad la encontramos en la tinción, los cortes de plastinados necesitaban más tiempo de exposición.

En general las piezas plastinadas mostraron un bajo nivel de detalle a la observación microscópica, los mejores resultados se obtuvieron utilizando azul de metileno, el cual, al ser hidrofóbico tiene mayor afinidad por el tejido plastinado que se encuentra deshidratado. Sin embargo, la data de muerte del cadáver y el hecho que ésta haya sido sometido a procesos de conservación previos a la plastinación probablemente explican los resultados obtenidos, siendo necesarios estudios que permitan evaluar de mejor manera la utilidad de piezas plastinadas para examen microscópico.

SUAZO, G. I. C \&. ROA, H. I. J. Microscopic anatomy of the salivary glands for mean of conventional and not conventional histologic technique. Int. J. Morphol., 26(3):689-695, 2008.

SUMMARY: The techniques of fixation and conservation allow to stop the processes of tissues disorganization and they are necessary to analyze the microscopic anatomy of them. The purpose of this study was to analyze the histologic characteristic of the parotid and submandibular glands obtained from three human cadavers fixed and conserved by means of: a) conservative solution based on formaldehyde (Sample I) and b) camera of cold for 12 hours (Sample II), both samples processed for hematoxilin-eosin (H-E); c) plastination with epoxic resin (Sample III) and processed for $\mathrm{H}-\mathrm{E}$ and with methylene blue - eosin without previous inclusion. The characteristics of the adenomer and glandular ducts system were analyzed. The best characteristics were in the sample II, with a good detail level in the glandular parenchyma, a greater basophilia was presented in the sample I. The sample III it presented a low detail level to the microscopic observation, the best results were obtained using methylene blue. The biggest difficulties in the histologic process of the plastinated specimens were in the cut and time for tintion. The results suggest that it is possible to obtain histologic preparations from autopsies in fixed cadavers and conserved for teaching and anatomical investigation.

KEY WORDS: Histologic technique; Plastination; fixation; Conservation; Salivary glands. 


\section{REFERENCIAS BIBLIOGRÁFICAS}

Bose, W. Method and results of plastination for macromorphologic studies. ZWR, 94: 696-7, 1985.

Bravo, H. Plastinación, una Herramienta Adicional para la Enseñanza de la Anatomía. Int. J. Morphol., 24(3):475480, 2006.

Cohn, F. Re-inventing anatomy: the impact of plastination on how we see the human body. Clin Anat., 15: 443-4, 2002.

Cook, P. Sheet plastination as a clinically based teaching aid at the University of Auckland. Acta Anat (Basel), 158: 33-6, 1997.

Dhingra, R.; Taranikanti, V. \& Kumar, R. Plastination: teaching aids in anatomy revisited. Natl. Med. J. India, 19: 171, 2006.

Eckel, H. E.; Sittel, C.; Walger, M.; Sprinzl, G. \& Koebke, J. Plastination: a new approach to morphological research and instruction with excised larynges. Ann. Otol. Rhinol. Laryngol., 102: 660-5, 1993.

Graf, J.; Schneider, U. \& Niethard, F. U. Microcirculation of the Achilles tendon and significance of the paratenon. A study with the plastination method. Handchir Mikrochir Plast Chir, 22:163-6, 1990.

Hoch, J.; Fritsch, H. \& Lewejohann, S. Plastinationhistological investigations on the inserting extensor pollicis brevis tendon on the proximal phalanx of the thumb. Ann. Anat., 186:311-5, 2004.

Kcn, Priya, K.; Lama, S. \& Magar, A. Plastination - an unrevealed art in the medical science. Kathmandu Univ. Med. .J (KUMJ), 5:139-41, 2007.

Latorre, R. M.; Garcia-Sanz, M. P.; Moreno, M. et al. How useful is plastination in learning anatomy? J. Vet. Med. Educ., 34:172-6, 2007.

Lozanoff, S. Re-inventing anatomy: the impact of plastination on how we see the human body. Clin Anat, 15:441-2. 2002.

Nash. L.; Nicholson, H.; Lee, A. S.; Johnson, G. M. \& Zhang, M. Configuration of the connective tissue in the posterior atlanto-occipital interspace: a sheet plastination and confocal microscopy study. Spine, 30:1359-66, 2005.
O'Sullivan, E. \& Mitchell, B. S. Plastination for gross anatomy teaching using low cost equipment. Surg. Radiol. Anat., 17:277-81, 1995.

Seibold, R.; Eitel, F.; Waldner, H.; Brunner, U. \& von Hagens, G. A new application of plastination in bone histology. Unfallchirurg, 94:624-33, 1991.

Simank, H. G.; Graf, J.; Schneider, U.; Fromm, B. \& Niethard, F. U. Demonstration of the blood supply of human cruciate ligaments using the plastination method. Z. Orthop. Ihre. Grenzgeb., 133:39-42, 1995.

Sittel C.; Eckel, H. E.; Sprinzl, G. M. \& Stennert, E. Section plastination of the larynx for histology of whole organ sections. HNO, 44:370-5, 1996.

Sora, M. C.; Strobl, B.; Staykov, D. \& Traxler, H. Optic nerve compression analyzed by using plastination. Surg. Radiol. Anat., 24:205-8, 2002.

von Hagens, G. Impregnation of soft biological specimens with thermosetting resins and elastomers. Anat. Rec., 194: 247-55, 1979.

von Hagens, G.; Tiedemann, K. \& Kriz, W. The current potential of plastination. Anat. Embryol. (Berl), 175: 411$21,1987$.

Weiglein AH. Plastination in the neurosciences. Keynote lecture. Acta Anat (Basel), 158:6-9, 1997.

Weiglein, A. H. Preservation and plastination. Clin. Anat., 15:445, 2002.

Dirección para correspondencia:

Prof. Dr. Iván Suazo Galdames

Unidad de Anatomía Normal

Universidad de Talca

Avenida Lircay s/n oficina $\mathrm{N}^{\circ} 104$

Talca - CHILE

Email: isuazo@utalca.cl

Recibido : 15-06-2008

Aceptado: 20-08-2008 
